\title{
EFFECT OF OPERATING VARIABLES ON REGENERATION OF BASE-OIL FROM WASTE OIL BY CONVENTIONAL ACID-CLAY METHOD
}

\author{
M. M. Rahman ", T. A. Siddiquee, S. Samdani and K. B. Kabir \\ Department of Chemical Engineering, Bangladesh University of Engineering \& Technology, Dhaka-1000, Bangladesh
}

Received 5 June 2008; received in the revised form 16 June 2008

\begin{abstract}
Lubricating oil requirement is increasing day by day with the establishment of new industries, increase in number of vehicular transports and mechanization of agriculture. Generated waste oil can be considered as a source of pollution or as a resource depending on the methods of utilization and management. This study compares different enduses of waste oil and develops a pathway through which basic properties of the base-oil can be retrieved. In this study a pilot scale setup of conventional acid-clay technique was established to recover waste oil collected from different sources and a set of experimental runs were conducted by varying the different process variables. Effects of the operating variables on the product quality are also discussed in this article. The recovery of regenerated base-oil was found to be in between 62 to 66 percent from this experimental study.
\end{abstract}

Keywords: Waste Oil; Regeneration; Base-oil.

\section{INTRODUCTION}

Bangladesh is a developing country and industrial development is the thriving sector alongside agricultural development. Industrial development and installation of process plants are continuing to fulfil the demand of various products in the local market as well as in the foreign market. Lubricating oil is used in industries to reduce friction and wear between metallic surfaces, which move with respect to each other by separating the metallic surfaces with a thin film of the oil.

Transportation network is gradually expanding to the every nook of the country. Presently total number of registered auto vehicles in Bangladesh is around 1.2 million [1]. These vehicles change their engine oil after three months or three thousand kilometres mileage, which comes first. Generators, captive and large power plants and various types of production machineries having moving parts require lubricating oil.

The demand of finished lube oil in different sectors in Bangladesh is about 100,000 tonnes per year; of which $70 \%$ is used for gasoline engine oil, diesel engine oil, automotive gear oil, motor cycle engine oil and rest $30 \%$ is used as industrial oil and marine engine oil [2]. When used, blended lubricating oil goes through normal degradation and about $50 \%$ of it is consumed in the process. The rest of the oil picks up number of contaminants from the working environment, such as, residual components of engine fuels, solids from wear processes along with corrosion products and dirt, soot, combustion products etc. [3].

There are basically three options to deal with the regarding waste oil in the world: a) dumping the waste oil on land, garbage heap and sewerage system, b) regeneration of base-oil from waste oil and c) extracting of heat value of waste oil through combustion process.

Waste oil creates enormous problems if is improperly disposed in the environment (land, garbage heap, surface water, sewerage systems). Simply one gallon of waste oil can ruin the taste of a million gallons of drinking water. Films of oils on the surface of water prevent the replenishment of dissolved oxygen thereby hamper aquatic life, impair photosynthetic processes and block sunlight [4]. Studies showed that, significant long-term effects have been observed in freshwater fishes with concentration of oil of $310 \mathrm{ppm}$ and in marine life forms at concentration of oil of only 1 ppm [5].

Waste oil is also used as fuel for industrial furnaces. Combustion of waste oil destroys valuable resources and also represents a significant threat to the environment. All the toxic components present in the waste oil reach to the environment with the flue gas. In extreme cases, these contaminants damage the furnace, leading to increased environmental pollution [3]. Emission of $\mathrm{Zn}$ can be as high as 600 times and $\mathrm{Cu}$ can be 2100 times if waste oil is burnt instead of rerefining [6].

Waste oil can be a very valuable resource, if managed properly. It has very refined fractions of petroleum and its recovery possibilities are extremely high. Average crude oils have 3-8\% base-oil, whereas lube crudes typically have 12 $16 \%$ base-oil. This compares with $65-75 \%$ recoverable base-oil content in used automotive oils, which if burnt or dumped would mean the loss of a valuable natural resource. Re-refining of waste oil is energy efficient; less energy (about one third) 
is used to produce a gallon of base stock from waste oil than to produce the same gallon from crude oil. It is also environment friendly. Table 1 highlights the end disposition of the key contaminants (heavy metals) depending on whether the waste oil is combusted for heat recovery or recycled to regenerate base-oil. In case of regeneration of baseoil from waste oil is that the noxious compounds are solidified and stabilized due to their disposition as a solid and pose minimal environmental risks.

Table 1: Environmental Impact Characteristics (Based on Heavy Metals) for Waste oil Re-use Options [7]

\begin{tabular}{lcc}
\hline Pollutant & $\begin{array}{c}\text { Industrial Burning } \\
\text { for Heat Recovery }\end{array}$ & $\begin{array}{c}\text { Regeneration of } \\
\text { Base-oil }\end{array}$ \\
\hline Lead & $\begin{array}{c}50 \%+\text { to air and } \\
\text { balance to ash }\end{array}$ & $100 \%$ to asphalt \\
Cadmium & $\begin{array}{c}50 \%+\text { to air and } \\
\text { balance to ash } \\
\text { Chromium }\end{array}$ & $\begin{array}{c}50 \%+\text { to air and } \\
\text { balance to ash }\end{array}$ \\
Zinc & $\begin{array}{c}50 \%+\text { to air and } \\
\text { balance to ash }\end{array}$ & $100 \%$ to asphalt \\
\hline
\end{tabular}

In Bangladesh, now there are six Lube Oil Blending Companies, which are: Eastern Lubricant Blenders Ltd (ELBL), Mobil Jamuna Lubricants Ltd. (MJLL), Standard Asiatic Oil Company Ltd. (SAOCL), FUCHS, Pacific Oil (SINO) and Lube House with a total capacity of around 46,000 tonnes per year, and the rest of finished lubricants are imported by different importers under different brand name each year [2]. This amount of oil would produce about 50,000 tonnes of waste oil yearly.
The best way to manage this waste oil is to regenerate the base-oil from waste oil. Currently, there are three approved waste lube recycling plants in Bangladesh: Grease House, Chittagong, Khulna Allied, Khulna and Min oils Ltd, Savar, Dhaka. Jointly they produce about 5,500 tonnes recycled base-oil per year. All these plants follow conventional acid-clay method to reclaim waste oil.

This study has been aimed to regenerate baseoil from waste oil collected from different sources using conventional acid-clay technique. The effect of various operating variables on the properties of the regenerated base-oil has also been studied.

\section{EXPERIMENTAL}

A pilot scale setup was established for recovering waste oil. Figure. 1 shows the major steps involved in the rerefining process. Waste oil was collected from a variety of sources including spent lube oil from auto vehicles, machineries of different workshops and industries around Dhaka city. Collected oils were then mixed together to represent a complete spectrum of waste lube oil.

Pre-treatment involved removal of solid particles and water from the waste oil by gravity settling. Two separate layers of waste oil and water were formed in the gravity settler, wherefrom upper layer of waste oil was collected and sent to the next step for further treatment.

Catalytic cracking of waste oil took place at the atmospheric pressure and the duration was about 3.5 hours with zeolite as the catalyst. After catalytic cracking the oil was washed with water to remove carbon particles from the oil. Then the oil was heated at $140^{\circ} \mathrm{C}$ and atmospheric pressure for 1

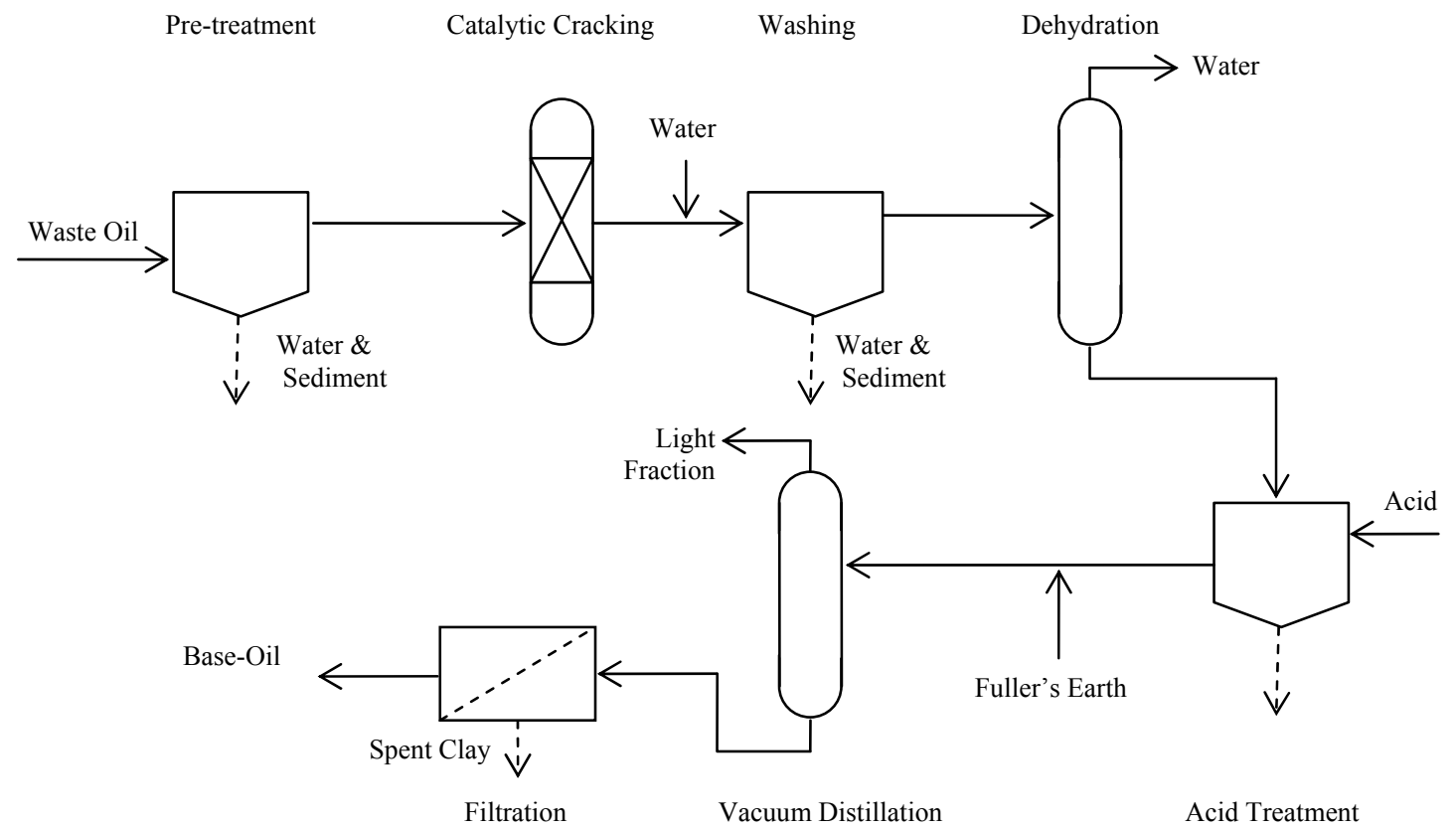

Figure 1: Base-Oil Regeneration Process 
to remove carbon particles from the oil. Then the oil was heated at $140^{\circ} \mathrm{C}$ and atmospheric pressure for 1 hour to remove residual free and emulsified water. Dehydrated oil was then cooled to about $30^{\circ} \mathrm{C}$ and treated with commercial grade sulphuric acid (about $92 \%$ ) and kept undisturbed for 24 hours for deasphalting and settling of acid sludge from acid treated oil. The oil was then mixed with fuller's earth and then fed to a vacuum distillation unit. Light fraction was collected from the top of the column. Bottom product of the column was filtered, to separate spent clay, and the filtrate was collected as rerefined base-oil.

\section{RESULTS AND DISCUSSION}

Four different sets of process variables was used to study their effects on regenerated lube oil properties. Only catalyst-waste oil ratio and cracking temperature of catalytic cracking unit and column pressure of vacuum distillation unit was selected for this purpose. Table 2 lists variation in these selected process variables for different runs.

For each run, regenerated base-oil was collected and analyzed. ASTM standard methods were used to determine various properties of the base-oil. Finally, the product was graded according to its viscosity by following ISO standard.

Properties of waste oil and regenerated base-oil are shown in Table 3.

Catalytic racking temperature was $180^{\circ} \mathrm{C}$ for the first run. $2^{\text {nd }}$ run was performed with same catalyst-waste oil ratio but at $130^{\circ} \mathrm{C}$. As the properties of the regenerated oil were found to improve, only catalyst-waste oil ratio was changed for the later runs. With increased catalyst-waste oil ratio, product viscosity index increased.

\section{Table 2: Process Variables}

\begin{tabular}{|l|l|l|l|l|}
\hline Process Variables & $\mathbf{1}^{\text {st }}$ Run & $\mathbf{2}^{\text {nd }}$ Run & $3^{\text {rd }}$ Run & $4^{\text {th }}$ Run \\
\hline Catalyst-waste oil ratio & $7.49 \mathrm{~g} / \mathrm{L}$ & $7.49 \mathrm{~g} / \mathrm{L}$ & $11.26 \mathrm{~g} / \mathrm{L}$ & $16.88 \mathrm{~g} / \mathrm{L}$ \\
\hline Cracking temperature & $180^{\circ} \mathrm{C}$ & $130^{\circ} \mathrm{C}$ & $130^{\circ} \mathrm{C}$ & $130^{\circ} \mathrm{C}$ \\
\hline Distillation time & 3 hours & 2 hours & 1.5 hours & 1 hour \\
\hline Distillation column pressure & $580 \mathrm{~mm} \mathrm{Hg}$ & $510 \mathrm{~mm} \mathrm{Hg}$ & $450 \mathrm{~mm} \mathrm{Hg}$ & $335 \mathrm{~mm} \mathrm{Hg}$ \\
\hline
\end{tabular}

Table 3: Waste and Regenerated Base-oil Properties

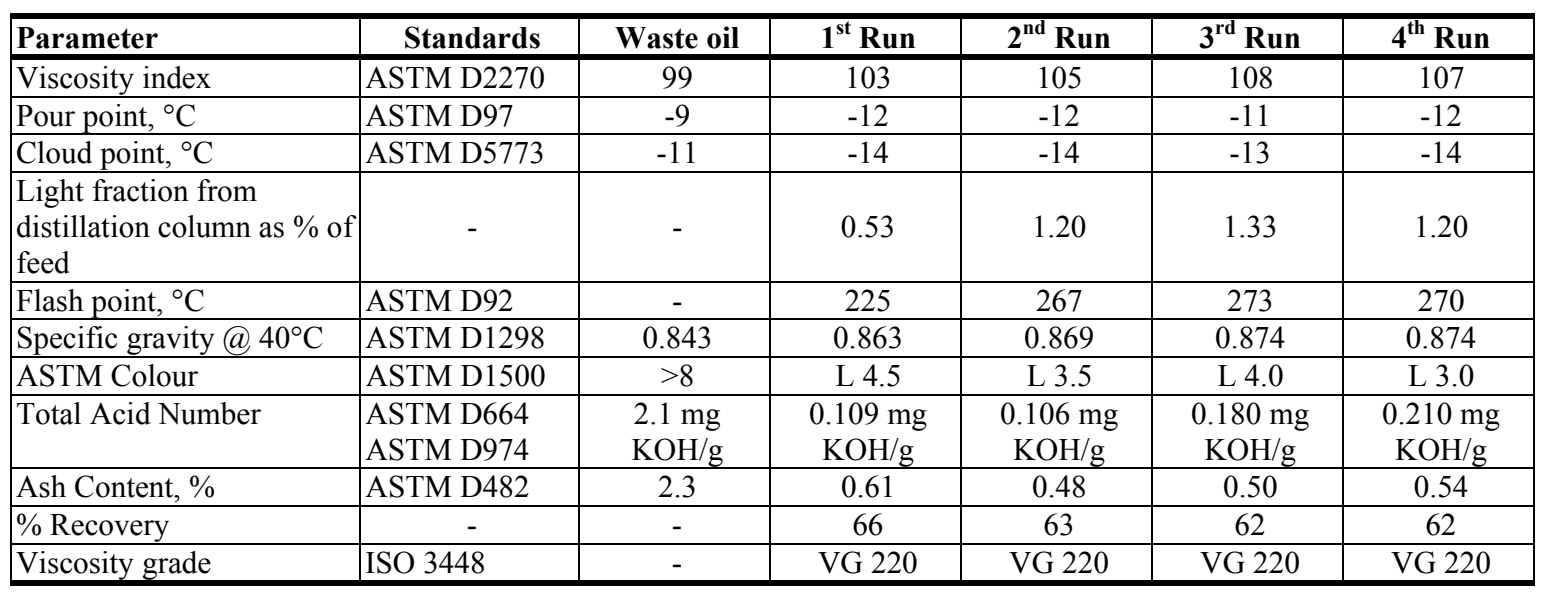


Petroleum products contain acidic constituents present as additives or as degradation products. Total acid number (TAN) is the quantity of base expressed in milligrams of potassium hydroxide per gram of sample, that is required to titrate a sample to a green/green-brown endpoint with $p$ napthanolbenzein indicator. Acid number is used as a guide in the quality control of lubricating oil and also as a measure of lubricant degradation in service [8]. Here, waste oil was found to have a TAN of 2.1 $\mathrm{mg} \mathrm{KOH} / \mathrm{g}$ while regenerated base-oils have values in between 0.1 and 0.21 . Specification of TAN for lube oils varies depending on its grade and end-use.

Ash-content of the products were high. After clay treatment and vacuum distillation the oil was filtered with coarse-filter cloth. Use of fine filter medium and adopting pressure filtration method ash content of the product can be substantially reduced.

Fuller's earth (clay) was used to neutralize acid-treated oil as well as for colour removal. Though same amount of clay was used for each run, the degree of mixing was not same. Addition of clay was followed by proper mixing of the clay with oil for all runs except 3. For these runs, colour removal can be correlated with amount of fuller's earth used. Use of more fuller's earth produced lighter base-oil. Colour of run 3 clearly showed the requirement of proper mixing for colour removal operation. However, usually regenerated base-oil is expected to have ASTM colour less than 2.0. Since, entrapped nitrogen in the oil is the main contributor for the colour of the oil, conventional acid-clay cannot be used to produce brighter baseoil of brighter quality. Hydrotreating the oil can produce base-oil of bright colour. However, hydrotreatment is a high pressure catalytic process and therefore not used.

Recovery of the base-oil was found to be in between 62 and 66 percent. This recovery was wellconnected with separation of impurities and light fractions as discussed earlier.

The regeneration process produced sludge in four stages: preliminary treatment, catalytic cracking, acid-treatment and filtration. If disposed to the environment, sludge separated in these steps can cause severe pollution as they are concentrated forms of contaminants. However, these sludges can be used as a modifier for bituminous materials. They can also be used for the preparation of carbon rods as they are rich in carbon content. Moreover, the sludge is completely combustible with net heating value amounting to $4,000 \mathrm{kcal} / \mathrm{kg}$ [9]. If burned, use of appropriate burners and methods for pollution abatement is necessary.

From the measured viscosities of the oils, all four products can be categorized as ISO VG220 [10]. Base-oil of this grade can be used for total loss systems. Typical examples are axles, railway points, rolling bearings, open gears, wire ropes, mechanical chains etc. $[11,12]$.

\section{CONCLUSION}

Every year, approximately 50,000 tonnes of waste oil is generated. Most of it is either disposed to the environment or burnt improperly contributing significant adverse effect to the environment. Proper collection and regeneration of waste oil can be beneficial to the nation by
A. reducing environmental pollution,
B. saving foreign exchange for importing virgin lube oils, and
C. conserving of mineral resources.

However, low profit and weak market structure drive the waste oil management method selection toward the untreated fuel oil market. Regeneration of waste oil and associated product markets should be patronized by the government.

\section{REFERENCES}

1. Siddiquee, T.A. and S. Samdani, Recycling of Used Lube Oil, in Department of Chemical Engineering. 2008, Bangladesh University of Engineering \& Technology: Dhaka.

2. Ahmed, N., Lube Oils and Bangladesh, in Probe News Magazine. 2007: Dhaka.

3. Kajdas, C., Major Pathways for Waste oil Disposal and Recycling. Part 1. Tribotest Journal, 2000. 7(1): p. 61-74.

4. Waste oil and Filter Recycling: City of Sierra Madre, California Homepage: http://cityofsierramadre.com. [Cited 31 May, 2008].

5. Environmental Regulations and Technology: Managing Used Motor Oil. 1994, U. S. Environmental Protection Agency: Cincinnati.

6. Boughton, B. and A. Horvath, Environmental Assessment of Waste oil Management Methods. Environmental Science \& Technology, 2004. 38(2): p. 353-358.

7. Graziano, D.J. and E.J. Daniels, Assessment of Opportunities to Increase the Recovery and Recycling of Waste Oil. 1995, US Department of Energy.

8. Speight, J.G., Handbook of Petroleum Product Analysis. 2002, Hoboken, NJ: John Wiley \& Sons, Inc.

10. Francois Audibert, Waste Engine Oils: Rerefining and Energy Recovery. 2006, Elsevier Science and Technology.

10. ISO 3448: 1975, Industrial Liquid Lubricants ISO Viscosity Classification, ISO: Geneva.

11. ISO 6743-99: 2002, Lubricants, Industrial Oils and Related Products (Class L) Classification, ISO: Geneva.

12. BDS 1637: 2000, Lubricants, Industrial Oils and Related Products (Class L) - Classification - Part 1: Family A (Total Loss Systems), BSTI: Dhaka. 